\title{
Keragaan Dan Pengembangan Agribisnis Kopi Robusta Di Provinsi Lampung (Studi Kasus : Kab Tanggamus)
}

\section{Robusta Coffee Agribusiness Development And Performance In Lampung Province (Case Study: Tanggamus Regency)}

\section{Valeriana Darwis ${ }^{1}$, Yonas Hangga Saputra, Chairul Muslim}

Pusat Sosial Ekonomi dan Kebijakan Pertanian

${ }^{1)}$ Email : valicfurca@gmail.com

\begin{abstract}
Lampung Province is one of the Robusta coffee agribusiness centers that is included in the development area of the coffee area contained in the Decree of the Minister of Agriculture No. 472 of 2018. Based on this stipulation, this paper aims to determine the production system, maintenance costs and supply chain in Lampung Province. The survey was conducted in July 2019 with data collection methods through FGD and direct interviews with farmers using a questionnaire. From the results of a qualitative descriptive analysis and maintenance cost, it was found that the Robusta coffee agribusiness in Lampung Province experienced positive growth. This is represented by an increase in coffee selling price of $0.39 \%$ / year, planting area of $0.33 \% /$ year and production of $0.09 \% /$ year. But in terms of productivity, respondents' farmers only produce $593 \mathrm{~kg} /$ year or still low compared to national productivity of $656 \mathrm{~kg} /$ year and Lampung province productivity of $800 \mathrm{~kg} /$ year. The low productivity of respondent farmers was caused by: (i) lack of motivation to maintain because the maintenance costs per $\mathrm{kg}(\mathrm{Rp} .4,013)$ were lower than the selling price of coffee (Rp. 18,000); (ii) the age of the plant is old and (iii) it is not the main crop. Coffee agribusiness in Lampung Province can still be improved by: (i) increasing productivity through the application of coffee-based cultivation; (ii) making demonstration plots at farmer locations as an effort to disseminate research results from the Ministry of Research and Development; (iii) rebuilding institutions especially in overcoming the problems of production, marketing and processing of products and (iv) making partnerships with traders or roasteries so that farmers no longer need to sell as origin seeds
\end{abstract}

Keywords: agribusiness and robusta coffee

Disubmit : 11 Oktober 2020; Diterima: 18 Oktober; Disetujui : 30 Oktober 2020

\section{PENDAHULUAN}

Tanaman kopi merupakan salah satu komoditas strategis di sektor perkebunan. Hal ini direpresentasikan dari nilai ekspor kopi peringkat ketiga tertinggi dibawah nilai ekspor tanaman kelapa sawit dan karet. Pada tahun 2017 negara tujuan eskpor kopi Indonesia terbesar ke Amerika Serikat (63,2 ribu ton), kemudian diikuti ke negara Jerman (44,7 ribu ton), Malaysia (43,1 ribu ton), Italia (38,1 ribu ton), dan Rusia (36,9 ribu ton) (Pusdatin Kementan Pusat Data dan Sistem Informasi Pertanian Kementerian Pertanian, 2018). Jenis kopi yang biasanya dibudidayakan di Indonesia adalah kopi Arabika dan kopi Robusta. Untuk 
kopi Robusta (Cofeea canephora) sendiri terbagi dalam tiga kelompok yaitu Guinean yang berasal dari Afrika Barat, Congolese yang berasal dari Aftika Tengah dan Conillion. Kopi Robusta yang berkembang di Indonesia sebagian besar kelompok Congolese yang memiliki cita rasa lebih baik sebagai pencampur kopi Arabika sehingga kopi Robusta asal Indonesia lebih digemari konsumen.

Meskipun bukan tanam asli Indonesia, tetapi perkembangan luas tanaman kopi nasional mengalami pertumbuhan positif yaitu meningkat dari 1,24 juta ha pada tahun 2016 menjadi 1,25 juta ha pada tahun 2017. Penambahan luasan tanam kopi berkorelasi positif dengan peningkatan produksi, yaitu meningkat dari 663,9 ribu ton pada tahun 2016 menjadi 668,7 ribu ton pada tahun 2017 (BPS, 2018). Dengan mendekati produksi 700 ribu ton pertahun, negara Indonesia menempati peringkat ke 4 negara penghasil kopi di dunia. Sementara negara yang paling banyak produksi kopi pertahunnya adalah Braziillia (2.054.000 ton) dan diperingkat selanjutnya adalah negara Vietnam (1.050.000 ton) serta Kolombia (750.000 ton) (Rubioyo et al 2019).

Kontribusi produksi kopi Indonesia di dunia bisa ditingkatkan apabila produktivitas kopi bisa dinaikkan. Produktivitas kopi nasional umumnya kurang 1 ton biji kering/ha/tahun dan produktivitas ini jauh dibawah produktivitas negara pesaing lainnya, seperti Vietnam produktivitas 2 ton/ha, bahkan Thailand bisa mencapai 3 ton/ha. Rendahnya produktivitas kopi disebabkan: (i) petani pada umumnya mempergunakan bibit berkualitas rendah, (ii) belum dikelola secara profesional, karena banyak diusahakan oleh perkebunan rakyat, (iii) adopsi teknologi budidaya kopi belum menyesuaikan agroekosistem spesifik lokasi dan masih mengandalkan teknologi tradisional, serta (iv) belum terbangunnya kelembagaan input dan output komoditas kopi secara holistik (Prastowo. et al 2010).

Total produsen kopi di Indonesia mencapai 205 perusahaan, namun sebagian besar adalah perusahaan dengan usaha skala kecil yang hanya menguasai pangsa pasar sebesar delapan persen. Menurut Bina UKM, rendahnya serapan industri kopi skala kecil karena kurang berinovasi dalam menciptakan diversifikasi produk yang saat ini olahannya sudah sangat beragam (Narulita et al 2014). Rendahnya inovasi pemanfaatan kopi karena petani hanya terbiasa menjual dalam bentuk biji dengan rantai pasok yang dimulai dari kebun petani, dijual ke pedagang dan kemudian diolah untuk kembali dipasarkan kepada konsumen.

Sementara yang dimaksud dengan rantai pasok menurut Ling Li (2007) adalah sekumpulan aktivitas dan keputusan yang saling tekait untuk mengintegrasikan pemasok, manufaktur, gudang, jasa transportasi, pengecer dan konsumen secara efisien. Untuk pertanian indikator keberhasilannya terlihat pada: (1) meningkatnya margin dan pengetahuan pasar bagi produsen; (2) penurunan hilangnya produk selama penyimpangan dan transportasi; (3) kualitas produk meningkat; (4) meningkatnya produk pangan yang terjamin aman; (5) penjualan meningkat signifikan; (6) peningkatan nilai tambah produk yang dapat menghasilkan penerimaan (Fizanty T 2012).

Dari uraian diatas maka tulisan ini bertujuan ingin melihat keragaan agribisnis kopi Robusta di Provinsi Lampung dengan memfokuskan pada sistem produksi, biaya pemeliharan tanaman dan rantai pasok. Selanjutnya memberikan saran pengembangan agribisnis kopi Robusta khususnya di Provinsi Lampung.

\section{METODE PENELITIAN}

\section{Lokasi}

Penelitian kopi Robusta di lakukan pada tahun 2019 dan pelaksanaan survay ke Kabupaten Tanggamus dilakukan pada bulan Juli. Pemilihan lokasi berdasarkan daerah sentra penghasil kopi Robusta yang masuk lokasi pengembangan kawasan kopi yang terdapat dalam Keputusan Menteri Pertanian Nomor 472 Tahun 2018. Penelitian ini mempergunakan data sekunder yang diperoleh dari dinas terkait dan data primer yang diperoleh melalui: (i) wawancara langsung mempergunakan kuesioner (pertanyaan terstruktur) dengan petani, pedagang, pengolah dan cafe/kedai kopi ; (ii) informasi permasalahan yang ada dalam industri/agribisnis kopi di Kabupaten Tanggamus dengan sistem Focus Discussion Group (FGD) yang 
dihadiri: 8 petani, 3 pedagang, 2 unit pengolah hasil, 3 petugas pendamping kehutanan, 2 orang dari Dinas Perkebunan Provinsi dan Kabupaten, 1 orang dari Dinas Koperasi dan Perdagangan Kabupaten, 3 peneliti dari BPTP Lampung dan 1 orang dari Bapeda Provinsi Lampung.

\section{Metode Analisis}

Untuk mengetahui Keragaan kopi Robusta mempergunakan analisis tabulasi dengan mempergunakan data sekunder. Sistem produksi kopi dianalisis secara deskriptif berdasarkan hasil FGD, rantai pasok mempergunakan analisis pemasaran dengan membandingkan biaya serta pendapatan di setiap rantainya dan biaya pemeliharaan mempergunakan analisis Harga Pokok Pemeliharaan (HPP)

Analisis Harga Pokok Pemeliharaan (HPP)

Harga pokok merupakan biaya-biaya yang seharusnya dikeluarkan untuk memproduksi suatu barang dalam satuan tertentu. Biaya merupakan pengorbanan sumber ekonomis yang diukur dalam satuan uang yang telah terjadi atau kemungkinan terjadi untuk mencapai tujuan tertentu (Zulkifli 1999). Sedangkan biaya produksi adalah biaya-biaya yang digunakan dalam proses produksi (Mulyadi 2007).

Tanaman kopi merupakan tanaman tahunan, oleh karena itu biaya yang dikeluarkan oleh petani adalah biaya pemeliharaan seperti : biaya pembelian pupuk dan obat-obatan, biaya tenaga kerja untuk memupuk, menyemprot dan memangkas. Untuk mengetahui berapa harga pokok pemeliharaan dalam satu kilogram kopi yang dihasilkan dipergunakan rumus seperti dibawah ini:

TBP

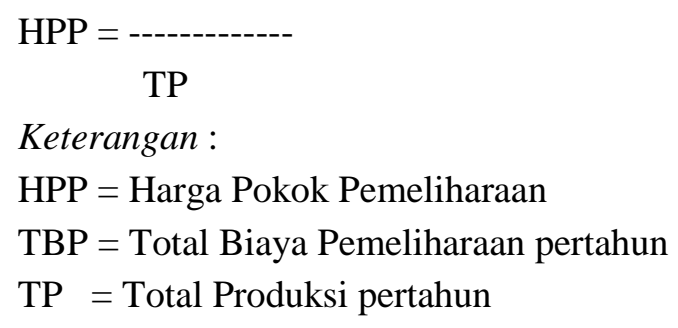

\section{Analisis Deskriptif Kualitatif}

Menurut Nazir (1988), metode deskriptif merupakan suatu metode dalam meneliti status sekelompok manusia, suatu objek, suatu kondisi, suatu sistem pemikiran ataupun suatu kelas peristiwa pada masa sekarang. Metode deskriptif merupakan metode yang digunakan untuk menggambarkan atau menganalisis suatu hasil penelitian tetapi tidak digunakan untuk membuat kesimpulan yang lebih

\section{HASIL DAN PEMBAHASAN}

Kopi di Indonesia pertama kali dibawa oleh pria berkebangsaan Belanda sekitar tahun 1646. Adapun jenis kopi yang dibawa adalah biji arabika mocca dari Arab (Prastowo et al, 2010). Tanaman kopi diusahakan oleh Belanda dan berhasil dibudidayakan di Pulau Jawa sekitar tahun 1699. Setelah hampir 100 tahun Java Coffee menjadi andalan ekspor pemerintah Belanda, pasca tahun 1876 terjadi penurunan produksi kopi jenis Arabika akibat serangan penyakit jamur Hemileia Vastratix $B$ dan serangan penyakit karat daun (coffee leaf rust).

Akibat penyakit ini, produksi kopi menurun sebesar lebih dari 60 persen. Untuk mengantisipasi kekurangan produksi kopi, maka sejak tahun 1900 pemerintah Belanda membudidayakan kopi jenis Robusta yang berasal dari Kongo, Afrika pada tahun 1900. Kopi jenis ini lebih tahan penyakit dan tidak memerlukan syarat tumbuh serta pemeliharaan yang ringan, dengan hasil produksi yang jauh lebih tinggi. Hal inilah yang menyebabkan kopi jenis ini lebih cepat berkembang di Indonesia (Panggabean, 2011). 


\section{Eskpor-Impor}

Menurut Rexsi Nopriyandi dan Haryadi (2017) harga kopi, PDB dan nilai tukar memiliki hubungan jangka pendek dan keseimbangan jangka panjang terhadap volume ekspor kopi. Berdasarkan estimasi jangka panjang variabel harga kopi, PDB dan nilai tukar tidak terlalu mempengaruhi volume ekspor kopi, sedangkan dalam jangka pendek ketiga variabel tersebut sangat mempengaruhi volume ekspor kopi. Agar komoditas kopi Indonesia lebih unggul di pasar internasional maka permasalahan peningkatan kualitas dan kuantitas menjadi penting.

Neraca perdagangan kopi Indonesia selama 6 tahun atau dari tahun 2012 sampai 2017 mengalami pertumbuhan positif, yaitu bertambah setiap tahunnya sebesar 6,3\% untuk jumlah kopi yang diekspor dan $1,5 \%$ untuk devisa yang diperoleh. Positifnya neraca ekspor-impor kopi ini disebabkan oleh peningkatan ekspor rata-rata 3,4 \%/thn dan penurunan impor sebesar 5,1\%/thn. Dalam kurun waktu yang sama rata-rata setiap tahun impor kopi sebesar 139.411 ton dan jumlah kopi yang diekspor rata-rata setiap tahun sebesar 458.649 ton (Statistik Harga Komoditas Pertanian 2018).

\section{Perkembangan Harga Kopi dan Konsumsi Nasional}

Menurut Kementerian Pertanian (2018) khusus harga produsen dalam masa 5 tahun (2013-2017) mengalami pertumbuhan positif dengan peningkatan harga rata-rata 9,12\%/thn. Dari 22 provinsi yang terdata, provinsi Yogyakarta merupakan provinsi yang mengalami rata-rata penurunan sebesar 2,33\%/thn. Adapun 21 provinsi lainnya mengalami pertumbuhan positif dengan provinsi yang paling tinggi mengalami peningkatan harga adalah Provinsi Aceh. Untuk provinsi sentra masing-masing mengalami peningkatan harga rata-rata pertahun sebesar 12,44\% (Sumatera Selatan) ; 5,57\% (Bengkulu) ; 0,39\% (Lampung) ; 4,47\% (Jawa Timur) dan 8,56\% (NTT).

Minum kopi kini sudah menjadi gaya hidup bagi anak-anak generasi millenial dan bukan sekedar minuman penghilang rasa kantuk. Ini tercermin dari menjamurnya kafe atau kedai-kedai penjual minuman dari seduhan bubuk kopi di seluruh nusantara. Kini untuk dapat menikmati kopi yang berkualitas tidak hanya di Starbucks atau di Coffee Bean. Sebab, kafe penjaja minuman kopi lokal kini telah hadir di mana-mana, dari pinggir-pinggir jalan, kawasan bisnis hingga ke mall.

Menurut data International Coffee Organization (ICO) Indonesia merupakan salah satu negara dengan konsumsi kopi terbesar di dunia. Konsumsi kopi Indonesia periode 2016/2017 mencapai 4,6 juta kemasan 60 $\mathrm{kg} / \mathrm{lb}(60 \mathrm{~kg}$ ) berada di urutan ke-6 negara dengan konsumsi kopi terbesar di dunia di bawah Rusia. Sementara konsumsi kopi terbesar di dunia adalah negara-negara yang tergabung dalam Uni Eropa dengan konsumsi lebih dari 42,6 juta lb (60 kg). Hal yang berbeda bila kita lihat perkembangan konsumsi perkapita didalam negeri. Pertumbuhan konsumsi perkapita dalam setahun dari tahun 2002 sampai 2015 justru mengalami penurunan rata-rata sebesar 1,66\% (Badan Pusat Statistik 2018).

\section{Luas Tanam, Produksi dan Produktivitas Kopi Robusta di Sentra Produksi}

Provinsi yang merupakan sentra produsen kopi Robusta di Indonesia berdasarkan luasannya pada tahun 2017 adalah: Sumatera Selatan (250.172 Ha), Lampung (161.954 Ha), Bengkulu (86.627 Ha), Jawa Timur (50.755 Ha) dan NTT (45.309 Ha). Dalam masa 3 tahun (2015-2017) menurut Badan Badan Pusat Statistik (2018) pertumbuhan rata-rata luas areal tanam kopi pertahun di lima provinsi sentra yang mengalami peningkatan adalah Provinsi Lampung $(0,33 \%)$ dan Sumatera Selatan $(0,13 \%)$. Sementara provinsi NTT, Jatim dan Bengkulu mengalami penurunan masing-masing sebesar 0,66\%;0,23\% dan 0,14\%. Meskipun Provinsi Sumatera Selatan mengalami peningkatan luas tanam, tetapi dari produksi justru mengalami penurunan sebesar 7,62\%. Penurunan produksi juga dialami oleh provinsi Jawa Timur sebesar 0,27\% dan di NTT sebesar 0,09\%. Sementara Provinsi Bengkulu dan Lampung mengalami penambahan produksi rata-rata pertahun sebesar $0,21 \%$ dan $0,09 \%$. 
Secara nasional produktivitas kopi Robusta pertahun sebesar $656 \mathrm{~kg}$ dan dalam perkembangannya selama 3 tahun (2015-2017) mengalami penurunan sebesar 0,45\% pertahun. Sementara produktivitas di provinsi sentra masing-masing sebesar: $536 \mathrm{~kg} / \mathrm{thn}$ di Sumatera Selatan ; $735 \mathrm{~kg} / \mathrm{thn}$ di Bengkulu ; 800 $\mathrm{kg} / \mathrm{thn}$ di Lampung; $710 \mathrm{~kg} / \mathrm{thn}$ di Jawa Timur dan $486 \mathrm{~kg} / \mathrm{thn}$ di NTT.

\section{Keragaan Kopi Robusta Lampung}

Secara umum permasalahan kopi robusta di Provinsi Lampung tidak optimal pertumbuhannya disebabkan karena: (i) Bibit yang dipergunakan pada umumnya adalah bibit asalan yang tidak bersertifikat, (ii) Pemakaian jenis dan dosis pupuk yang tidak sesuai dengan GAP, (iii) Kekurangan tenaga pengamat hama penyakit dan (iv) ketersediaan dan sistem pengairan. Secara khusus permasalahan agribisnis kopi yang ditemukan di Kabupaten Tanggamus dapat dilihat pada Tabel 1.

Tabel 1. Permasalahan Agribisnis Kopi di Kabupaten Tanggamus

\begin{tabular}{ll}
\hline \multicolumn{1}{c}{ Bagian } & \\
\hline Lahan & - Status lahan milik adat dan Perhutani \\
Usia & - Lahan kurang subur karena kandungan PH tanah semakin menurun \\
Budidaya & - Usia kopi banyak yang lebih dari 25 tahun \\
& - Jarak tanam tidak teratur, kerena kopi ditanam bersamaan dengan tanaman lainnya \\
& - Jenis dan dosis pemakaian pupuk tidak sesuai dengan anjuran \\
Teknologi & - Panen asalan \\
& - Sosialiasi teknologi budidaya dan pengolahan sudah diberikan, tetapi tidak maksimal dalam \\
& pelaksanaannya. hal ini disebabkan rendahnya tingkat SDM petani. \\
& - Teknologi budidaya kopi dilahan PH rendah, teknologi peremajaan dan peningkatan \\
Kelembagaan & produktivitas sudah dilakukan oleh BPTP, tinggal mempraktekkannya dilahan petani \\
Harga & - Petani masih berusaha sendiri dan belum ada kelompok tani \\
& - Harga kopi fluktuatif dan cenderung menurun \\
& - Tidak ada perbedaan harga antara petik merah dengan petik hijau \\
Pemasaran & - Belum memanfaatkan sitem Resi Gudang dalam mengatasi penurunan harga jual kopi \\
& - Dijual secara perorangan, belum berkelompok. \\
& - Hanya beberapa petani yang sudah menjalin kemitraan dengan pengolah/roastery/cafe kopi. \\
& - Belum mempergunakan internet, masih memasarkan dengan cara dari mulut ke mulut dan ikut \\
& beberapa festival yang diadakan oleh pemda \\
\hline
\end{tabular}

Sumber : Data Primer

\section{Analisis Harga Pokok Pemeliharaan Kopi Robusta}

Analisa harga pokok pemeliharaan kopi Robusta diperoleh dari hasil wawancara langsung dengan 8 petani yang berada di sekitar lokasi penelitian. Kegiatan yang biasanya dilakukan dalam pemeliharaan adalah: pemupukan, penyemprotan, pemangkasan dan panen. Dalam masa satu tahun biaya yang dikeluarkan oleh petani dalam kegiatan pemeliharaan sebesar Rp 2.379.857 (Tabel 2). Adapun biaya yang paling banyak dikeluarkan dalam memelihara kopi adalah pembelian pupuk urea, npk dan organik, yaitu sebesar Rp 981.286. Untuk biaya kedua yang terbanyak adalah biaya tenaga kerja (Rp 940.000) dan pembelian obatobatan (Rp. 458.571).

Jarak tanam masing-masing petani responden tidak sama, sehingga jumlah pohon dalam satu hektarpun tidaklah sama. Rata-rata jumlah pohon dalam satu hektar di petani responden sebanyak 1.307 pohon dan satu pohon rata-rata bisa menghasilkan $2,2 \mathrm{~kg}$ pertahun atau produksi totalnya dalam satu hektar sebanyak $593 \mathrm{~kg}$. Untuk menghasilkan produktivitas tersebut petani harus mengeluarkan biaya pemeliharaan sebesar Rp 2.379.857 atau biaya pemeliharaan untuk satu kilogram kopi yang dihasilkan sebesar Rp 4.013. 
Tabel 2. Harga Pokok Pemeliharaan Tanaman Kopi Perkilogram Dalam Luasan $1 \mathrm{Ha}$

\begin{tabular}{|c|c|c|c|c|}
\hline No & Uraian & Jumlah & Harga (rp/unit) & Nilai \\
\hline 1. & Pupuk UREA (kg) & 37,14 & 2.000 & 74.286 \\
\hline 2. & Pupuk NPK (kg) & 154,76 & 3.000 & 464.286 \\
\hline 3. & Pupuk Organik (kg) & 553,39 & 800 & 442.714 \\
\hline 4. & Obat-obatan & - & - & 458.571 \\
\hline 5 & Tenaga Kerja (Org) & 9,37 & 70.000 & 655.714 \\
\hline \multirow[t]{2}{*}{6.} & Panen (org) & 4,06 & 70.000 & 284.286 \\
\hline & Jumlah & & & 2.379 .857 \\
\hline 7 & Jumlah Pohon (batang/ha) & & & 1.307 \\
\hline 8 & Produksi $(\mathrm{kg})$ & & & 593 \\
\hline 9 & Produktivitas (batang/kg) & & & 2,2 \\
\hline 10 & Biaya Pemeliharaan (perkg) & & & 4.013 \\
\hline
\end{tabular}

\section{Rantai Perdagangan dan Analisis Rantai Pasok di Kabupaten Tanggamus}

Secara umum rantai pemasaran kopi robusta di lokasi penelitian ada tiga pola, yaitu: (i) petani menjual biji kopi ke pedagang pengumpul ; (ii) petani menjual ke unit pengolah hasil (UPH) dan (iii) petani menjual langsung ke roastery (café kopi khusus). Masing-masing pola pemasaran tersebut memiliki perlakuan yang berbeda. Untuk pola satu petani menjual dalam bentuk kopi asalan dan dijual dengan harga Rp 18.000/kg. Untuk pola pemasaran kedua petani menjual biji kopi petik merah dengan kadar air 12 sd 15. Biji kopi ini bisa laku dijual seharga Rp 30.000 perkilogramnya. Untuk pola ketiga petani menjual ke roastery dengan perlakukan khususnya, seperti biji kopi yang diolah melalui proses Fullhouse dan dijual dengan harga Rp Rp. 45.000 perkilogramnya

\section{Pola 1}

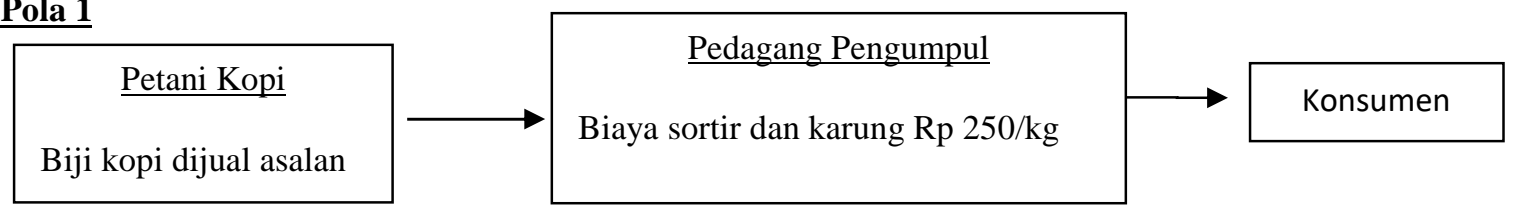

$\underline{\text { Pola } 2}$

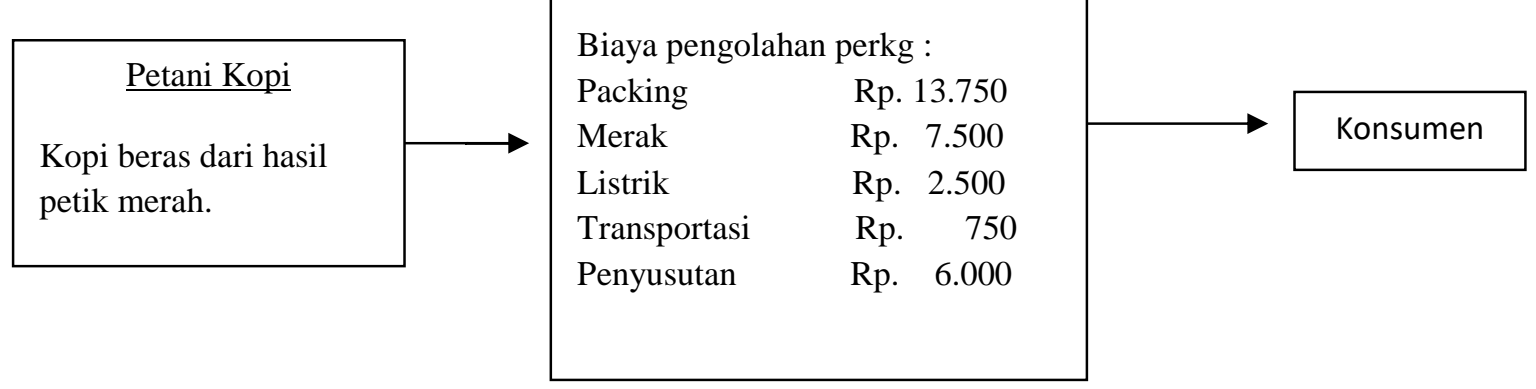




\section{$\underline{\text { Pola } 3}$}

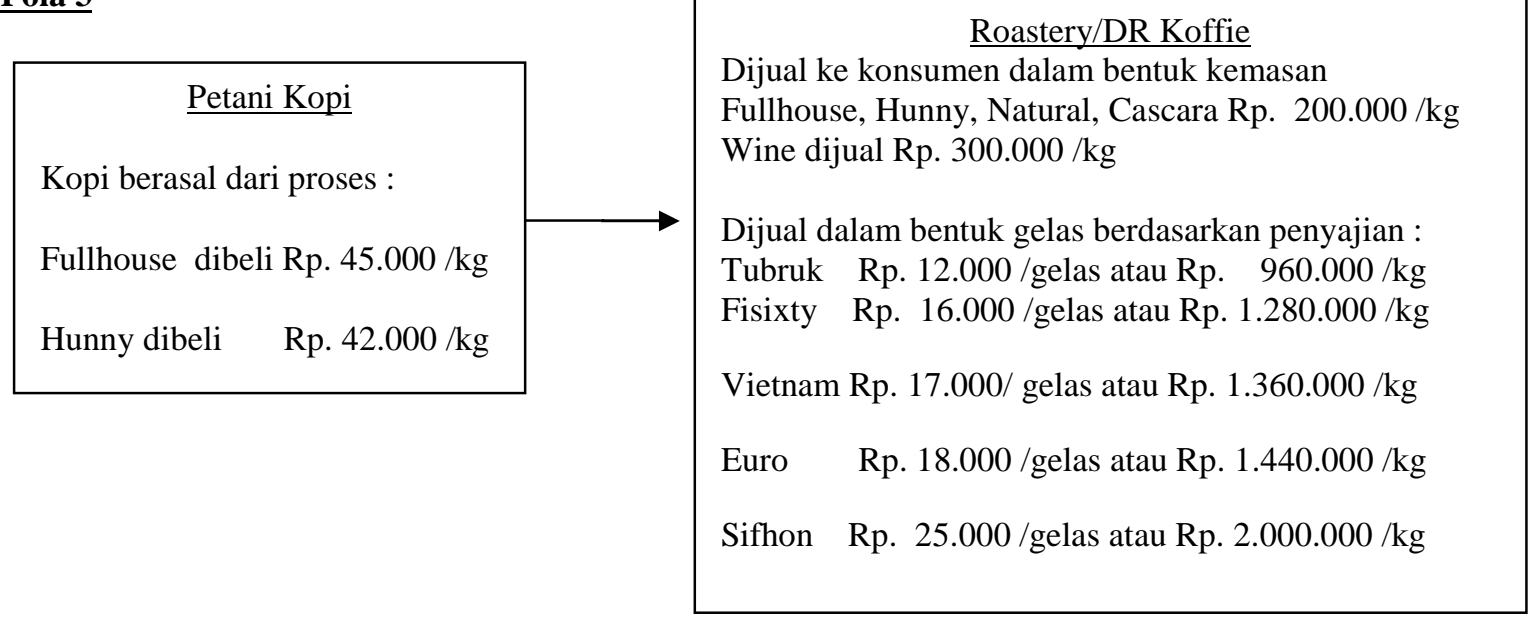

\section{Dr. KOFFIE Roastery/Café Kopi Binaan Dinas Perkebunan Provinsi}

DR KOFFIE bersentuhan dengan Dinas Perkebunan Provinsi Lampung dimulai pada saat diadakannya festival kopi Lampung pada tahun 2016. Pertemuan tersebut kemudian berlanjut pada beberapa kegiatan lainnya, seperti: coffe robusta meeting dan uji coba rasa kopi seprovinsi Lampung. Dari beberapa kali pertemuan tersebut akhirnya DR KOFFIE termasuk pelaku kopi yang dibina oleh Dinas Perkebunan. Adapun bentuk binaan yang sudah disosialisasikan antara lain: praktek budidaya berdasarkan GAP, GMP, pasca panen serta diperkenalkan kepada organisasi kopi internasional (SCOPI).

Banyak ilmu pengetahuan yang diperoleh kemudian di praktekkan dalam usaha bisnis kopi dengan cara melakukan pembinaan dan pengawasan langsung kepada petani kopi yang akan memasok kopi ke kafe DR KOFFIE. Pembinaan awalnya dimulai pada tahun 2016 ke satu orang petani yang berada di Kabupaten Tanggamus. Areal kopi yang dibina pada awalnya seluas 2 Ha, kemudian pada tahun 2017 menjadi 3 ha dan posisi sekarang sudah berhasil membina petani sebanyak 10 orang di luasan 10 Ha. Lahan binaan tersebut berada dalam satu hamparan yang letaknya diperbatasan Kabupaten Tanggamus dan Kabupaten Lampung Barat.

Pengontrolan kopi ke petani binaan dilakukan pada saat musim panen, yaitu dari bulan April sampai September. Dalam budidayanya petani mempergunakan varietas Lengkong, Lokal, Tugu Biru, Tugu Kuning dan Tugu Sari. Biji yang dibeli adalah biji petik merah yang dikumpulkan dalam satu varietas dalam bentuk greenbean, selanjutnya greenbean tersebut diolah menjadi rosting dengan kadar air sebesar 12 sampai 13 . Kegiatan roosting menjadi penting bagi pemilik café karena roosting merupakan salah satu proses penting yang akan mempengaruhi kualitas aroma dan rasa dari kopi. Bahkan secara persentase proses roosting memiliki pengaruh hingga 30\% dalam sumbangan aroma dan rasa kopi.

Greenbean yang dibeli ke petani dibedakan mengikuti proses yang dilakukan. Untuk kondisi sekarang harga beli perkilogram dengan proses: (i) Fullhouse senilai Rp 45.000 ; (ii) Hunny senilai Rp 42.000 ; (iii) Wine senilai Rp 50.000 ; (iv) Natural senilai Rp 47.500 dan (v) Cascara senilai Rp 25.000. Kopi tersebut kemudian dimasukan dalam bungkusan dengan ukuran 100 gram dan dijual perbungkus dengan harga Rp. 30.000 untuk Wine Proses dan Rp. 20.000 perbungkus untuk 4 proses yang lain. Dalam satu bungkus kopi bisa diseduh atau disajikan sebanyak 8 kali.

Kopi yang sudah dibungkus dijual dalam bentuk oleh-oleh (50\%) dan dikonsumsi langsung (50\%). Defenisi konsumsi langsung ini adalah konsumen datang minum kopi di warung DR KOFFIE yang ada di Lampung, Bogor dan Depok, atau ke warung-warung kopi lainnya yang rutin memesan setiap minggu ke DR 
KOFFIE. Konsumen yang minum di DR KOFFIE paling banyak anak-anak muda dibawah usia 30 tahun (70\%). Dalam kafe DR KOFFIE harga yang dijual pergelasnya berbeda mengikuti proses penyeduhan dan penyajiannya, yaitu : (i) tubruk seharga Rp 12.000 ; (ii) fisixsty $\mathrm{Rp} 16.000$; (iii) europroses seharga $\mathrm{Rp}$ 18.000 ; (iv) sifhon seharga Rp 25.000 dan Vietnam trip seharga Rp 17.000. Dalam satu minggu rata-rata kopi yang laku terjual antara 50 sampai 60 kilogram.

\section{KESIMPULAN DAN SARAN}

Produktivitas kopi ditingkat petani masih rendah, hal ini disebabkan oleh: (i) kurang motivasi memelihara karena biaya pemeliharaan perkg ( $\mathrm{Rp} 4.013)$ lebih rendah dibandingkan harga jual kopi (Rp 18.000) ; (ii) usia tanaman sudah tua dan (iii) bukan merupakan tanaman utama, karena ditanam bersamaan dengan komoditas lain pada lahan yang sama.

Agribisnis kopi di Provinsi Lampung masih dalam pertumbuhan positif, hal ini terlihat dari adanya peningkatan harga jual, luas tanam dan produksi. Agribisnis kopi di Provinsi Lampung masih bisa ditingkatkan lagi dengan cara: (i) meningkatkan produktivitas melalui penerapan budidaya berdasarkan GAP kopi ; (ii) membuat demplot dilokasi petani sebagai upaya dalam mensosialisasikan hasil penelitian dari Litbang Kementan ; (iii) membangun kembali kelembagaan khususnya dalam mengatasi masalah produksi, pemasaran dan pengolahan hasil serta (iv) membuat kemitraan dengan pedagang atau roastery sehingga petani tidak perlu lagi menjual dalam bentuk biji asalan

\section{Daftar Pustaka}

Badan Pusat Statistik. 2018. Survei Sosial Ekonomi Nasional (SUSENAS) Tahun 2018. Jakarta (ID).

Fizanty T, Kusnandar. 2012. Pengelolaan Logistik Dalam Rantai Pasok Produk Pangan Segar Di Indonesia. Jurnal Penelitian Pos Dan Informatika.

Kementerian Pertanian. 2018. Statistik Harga Komoditas Pertanian Tahun 2019. Jakarta (ID): Kementerian Pertanian.

Ling Li. 2007. Supply Chain Management: Concep, Techiniques and Pratices Enhancing Value Through Collaboration. Singapore: World Scientific Publishing. Co.Pte. Lted.

Mulyadi. 2007. Akuntasi Biaya. Sekolah Tinggi Ilmu Manajemen YKPN. Yogyakarta (ID).

Narulita, Sari, Ratna Winandi, and Siti Jahroh. 2014. "Analisis Dayasaing Dan Strategi Pengembangan Agribisnis Kopi Indonesia.” Jurnal Agribisnis Indonesia 2(1): 63.

Nazir, M. 1988. Metode Penelitian, Ghalia Indonesia. Jakarta (ID.

Panggabean Edy. 2011. Buku Pintar Kopi. Jakarta (ID: PT. AgroMedia Pustaka.

Prastowo, Bambang, Elna Karmawati, Rubijo, Siswanto, Chandra Indrawanto, S. Joni Munarso. 2010. Budidaya Dan Pasca Panen Kopi.

Pusdatin Kementan Pusat Data dan Sistem Informasi Pertanian Kementerian Pertanian. 2018. Ekspor Komoditi Pertanian Berdasarkan Negara Tujuan. Jakarta (ID).

Rexsi Nopriyandi. Haryadi. 2017. Analisis Ekspor Kopi Indonesia Paradigma Ekonomika Vol. 12(1). 
Darwis dkk : Keragaan dan Pengembangan Agribisnis Kopi Robusta di Provinsi Lampung.

Rubioyo, Hermanto, C Indrawanto, M Yusron, V Darwis, T Anggraeni, K Hadiutomo dan Y Nurcahya. 2019. Pemetaan Dan Reviu Proses Bisnis Perencanaan Wilayah Perkebunan Kopi Di Indonesia. Biro Perencanaan Kementerian Pertanian.

Statistik, Badan Pusat. 1392. STATISTIK INDONESIA 2018. Indonesia.

Sugiyono. 2005. Metode Penelitian Administrasi. Bandung: Alfabeta.

Whitney.F. 1960. The Element Of Research. New York: Prentice-Hall, Inc.

Zulkifli, Sulastriningsih dan. 1999. Akuntansi Biaya. Seolah Tinggi Ilmu Manajemen YKPN. Yogyakarta (ID). 